\title{
A apreciação cambial e a Dívida Líquida do Setor Público
}

Fábio Henrique Bittes Terra ${ }^{*}$

\section{Introdução}

A taxa de câmbio em janeiro de 2004 era de $R \$ 2,85$ para US\$1. Em fins de março de 2007 esta mesma taxa era de $R \$ 2,08$ para US $\$ 1^{19}$. Ou seja, em pouco menos de 40 meses houve uma depreciação acumulada no valor da moeda americana de 37\%.

Por sua vez, a Dívida Líquida do Setor Público, doravante DLSP, tem seu comportamento influenciado, de maneira direta, pela dinâmica da taxa de câmbio por intermédio de três mecanismos: via parcela da dívida interna indexada à taxa de câmbio, pelo estoque total da dívida externa, e pelas reservas internacionais.

Desta forma, a apreciação cambial tem reflexo direto nos fatores condicionantes do endividamento do setor público. Logo, o objetivo deste artigo é analisar quais os efeitos da valorização do real sobre a DLSP. É examinado, por razões de espaço físico e existência de dados, o período 01/2004 a 03/2007.

Além desta breve introdução, a seção 2 exprime as causas da apreciação cambial. A seção 3 apresenta a DLSP, seu conceito e componentes. A seção 4 mostra a relação entre a DLSP e o câmbio. Finalmente, a seção 5 tece breves conclusões sobre a apreciação cambial e a DLSP.

\section{As causas da valorização cambial}

A taxa de câmbio desvalorizou-se substancialmente em 2002 devido à incerteza nas expectativas do mercado, concernentes à eleição presidencial que se realizaria em outubro de 2002. Existia no período que antecedia a eleição presidencial certa ansiedade do mercado para saber quem seria o novo presidente, e quais os rumos das políticas econômicas por ele adotadas. As pesquisas eleitorais apontavam a vitória do candidato Luis Inácio Lula da Silva, sabido político de esquerda, o que causou apreensão aos investidores. Houve fuga de capitais, induzindo ao aumento da taxa de câmbio. Esta saiu de um patamar de R 2,37 em janeiro, para $R \$ 3,81$, por dólar, em outubro de 2002. Isto corresponde a uma valorização da moeda americana de $61 \%$ em 10 meses.

\footnotetext{
* Mestrando do Programa de Pós-Graduação em Desenvolvimento Econômico da Universidade Federal do Paraná (PPGDE/UFPR). Endereço eletrônico: fhbterra@yahoo.com.br .

19 Dados do IPEADATA. Taxa de câmbio comercial, média, mensal e para a compra.
} 
Já em fins de 2002, passada a eleição presidencial, o real iniciou uma trajetória de valorização que perdura até os dias de hoje, após o presidente eleito anunciar que não iria alterar o perfil da política econômica. Houve influxo de capitais ao país e restabeleceu-se um real mais valorizado. No período que se estende de janeiro de 2003 até maio de 2007, o real se valorizou $73 \%{ }^{20}$.

Para fazer frente à fuga de capitais em 2002, o Brasil viu-se obrigado a elevar a taxa de juros, aumentando o diferencial entre juros internos e externos. A maior taxa de rentabilidade oferecida pela economia brasileira, auxiliou no retorno ao país do fluxo internacional de capitais, o que contribuiu para a depreciação da taxa de câmbio.

A apreciação cambial é ainda intensificada pelo atual ciclo de liquidez internacional, que faz com que países em desenvolvimento recebam uma quantidade maior de recursos externos. Como prova disto, se verifica a valorização das moedas locais em todos os países em desenvolvimento ${ }^{21}$, porém em nenhum deles em tamanho análogo ao que ocorre no Brasil.

Além desses fatores acima descritos, a melhoria dos fundamentos macroeconômicos brasileiros (relação DLSP/PIB estável, relações Reservas/Div. Externa e Exportações/Div. Externa favorável, entre outros) tem reduzido o risco-país e suavizado a percepção de risco dos investidores, o que tem atraído maior quantidade de capitais para o país. Desta forma, aumenta-se a oferta de dólar e há pressão por baixa na taxa de câmbio.

Soma-se a estes movimentos financeiros favoráveis os bons resultados da balança comercial brasileira, incentivados pelo ciclo de expansão da economia mundial e pelos bons preços das principais commodities de exportação do Brasil. O superávit auferido pela conta comercial do Balanço de Pagamentos é um dos principais mecanismos de entrada de recursos externos no país, o que aprecia a taxa de câmbio.

Todos estes fatores reunidos explicam a forte apreciação da taxa de câmbio no período pós-2003. A apreciação não tem sido superior devido às intervenções do Banco Central no mercado de câmbio, em operações de compra de moeda estrangeira, visando compor reservas internacionais.

20 Todos os dados IPEADATA. Taxa de câmbio comercial, média, mensal e para a compra.

21 Segundo informes do Fundo Monetário Internacional, www.imf.org 


\section{A Dívida Líquida do Setor Público (DLSP)}

A DLSP (utiliza-se neste artigo o critério de Dívida Líquida do Setor Público Consolidado) é todo o débito - passivo - que possui o setor público não financeiro com o setor público financeiro, com o setor privado financeiro e não-financeiro, e com o resto do mundo. Do total de débitos, subtraídos os ativos públicos e privados - créditos - em poder do setor público, tem-se o montante da DLSP.

O setor público consolidado engloba todas as esferas governamentais - União, estados e municípios - a Previdência Social, o Banco Central do Brasil e as empresas estatais - federais, estaduais e municipais. Com exceção do Banco Central, nenhuma outra instituição financeira pública compõe o setor público consolidado.

Os principais passivos componentes da DLSP são: a base monetária, que é o passivo monetário do Banco Central; a dívida mobiliária federal (DMF), total de títulos públicos emitidos pelo Tesouro Nacional, vendidos, cotados e resgatados em moeda nacional; a dívida externa líquida, que são desembolsos contratuais realizados com o setor externo, composta por uma gama de moedas estrangeiras, porém somente contabilizada em reais após serem convertidas em dólar americano ${ }^{22}$.

Os créditos do setor público não-financeiro são ativos que ele possui, que são passivos para o setor privado financeiro e não-financeiro, setor público financeiro e o setor externo.

Matematicamente a DLSP pode ser definida por:

$D L S P=M+B+e I-A+e F-e R$,

Tem-se que: $M$ é a base monetária, $B$ é a dívida interna indexada à taxa de juros ou algum outro índice interno, e é a taxa de câmbio, $I$ é a dívida interna indexada à taxa de câmbio, $A$ são os ativos financeiros do setor público, $F$ e $R$ são a dívida externa e as reservas internacionais, respectivamente. Nota-se que $A$ e $\mathrm{R}$ aparecem com sinal negativo, pois se subtraem do montante da dívida bruta, visto que são ativos - créditos - do setor público consolidado.

Os três mecanismos de influência do câmbio sobre a DLSP estão apresentados. O termo eI mostra como a DLSP varia a partir da indexação de títulos públicos à taxa de

22 A DLSP conta ainda com outros passivos, de menor relevância, ocorrência e montante. Exemplos destes são: dívida bancária dos governos central, estadual e municipal; dívidas securitizadas do governo central; recursos do FAT; arrecadações a recolher. Para mais ver Manual de Estatísticas Fiscais do Depec/Bacen - junho de 2006. Disponível em http://www.bcb.gov.br/ftp/infecon/Manual.pdf 
câmbio, $e \mathrm{~F}$ e $e \mathrm{R}$ mostram a variação do estoque de dívida externa e reservas internacionais, respectivamente, quando se altera a taxa de câmbio.

\section{A relação taxa de câmbio - DLSP}

Tendo em mente a formalização acima, os termos eI e $B$ representam a DMF, componente majoritário da DLSP. Os títulos públicos conferem ao seu detentor, em uma determinada periodicidade, uma rentabilidade, que é estipulada por meio do indexador do título. Os quatro principais indexadores da DMF, entre 2004 e março de 2007, foram: a taxa SELIC, os indexadores pré-fixados, a taxa de câmbio e os índices de preço.

Interessa a este trabalho a parcela da DMF indexada à taxa de câmbio ${ }^{23}$. Como apresenta o gráfico 1, a indexação cambial dos títulos públicos reduziu-se significativamente no período. De um total de 10,8\% dos títulos emitidos em janeiro de 2004, chega-se, em março de 2007, a 1,26\% da DMF, em posição de carteira, indexada à taxa de câmbio.

A menor emissão de títulos cambiais leva a uma melhora no perfil da DMF. As finanças públicas ficam menos sujeitas a serem afetadas, caso ocorra alguma adversidade na economia mundial, visto que o Brasil tem um mercado de câmbio flutuante, adstrito às oscilações do mercado. A apreciação cambial determina uma menor pressão sobre a DMF, pois reduz o dispêndio em reais para o pagamento dos títulos vinculados ao câmbio.

Gráfico 1. DLSP - Participação do Indexador Cambial - Sem swap, em posição de carteira - mensal em \% do total de títulos emitidos (2004 - 03/2007)

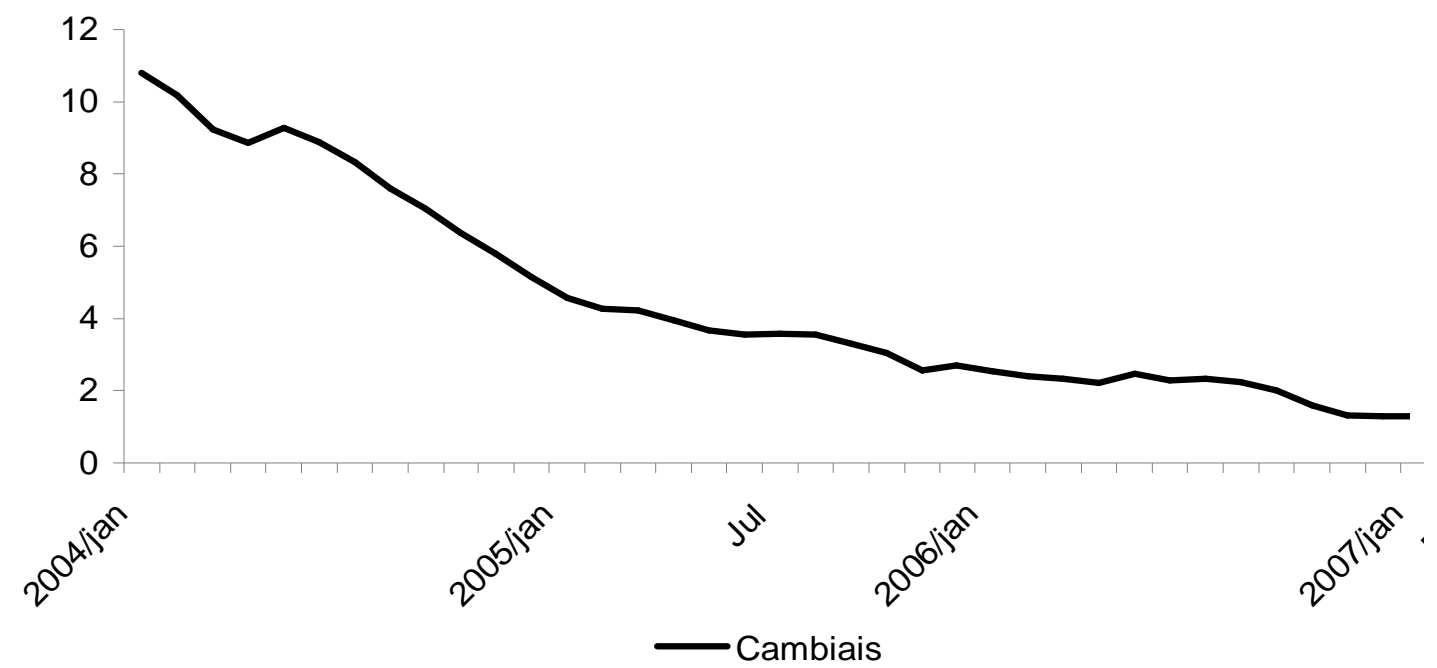

Fonte: Banco Central do Brasil

23 Os principais títulos cambiais são: Bônus do Tesouro Nacional (BTN); as Notas do Tesouro Nacional (NTN) séries M, A, D, I e R; as Notas do Banco Central (NBC) séries E e F; e os títulos FAT-cambiais. 
Em termos da dívida externa, a apreciação do real frente ao dólar faz com que o estoque desta dívida se desvalorize. A dívida externa não está contratada apenas em dólar, é composta por uma cesta de moedas. Todavia, para a apuração de seu estoque, toda esta cesta é convertida primeiramente em dólar americano para depois ser contabilizada na moeda nacional. Com o real valorizado frente ao dólar, o estoque da dívida externa é reduzido pelo ajuste cambial.

Ademais, o movimento de composição de reservas internacionais, como pode ser visto pelo gráfico 2 , tem influenciado uma queda vertiginosa no montante da dívida externa líquida $^{24}$. As reservas internacionais apresentaram crescimento tal, que em 2005 a posse de ativos estrangeiros pelo setor público superou seu passivo externo.

Em vista disso, parte da estabilidade atual da relação DLSP/PIB é explicada pelo movimento recente do endividamento externo. Sua dinâmica tem sido positiva à DLSP, dado que hoje o Brasil tem um saldo de débitos externos inferior a seu saldo de créditos externos. A apreciação cambial está intrinsecamente ligada a este comportamento: por um lado desvaloriza o estoque do passivo externo e por outro lado favorece a composição de reservas internacionais.

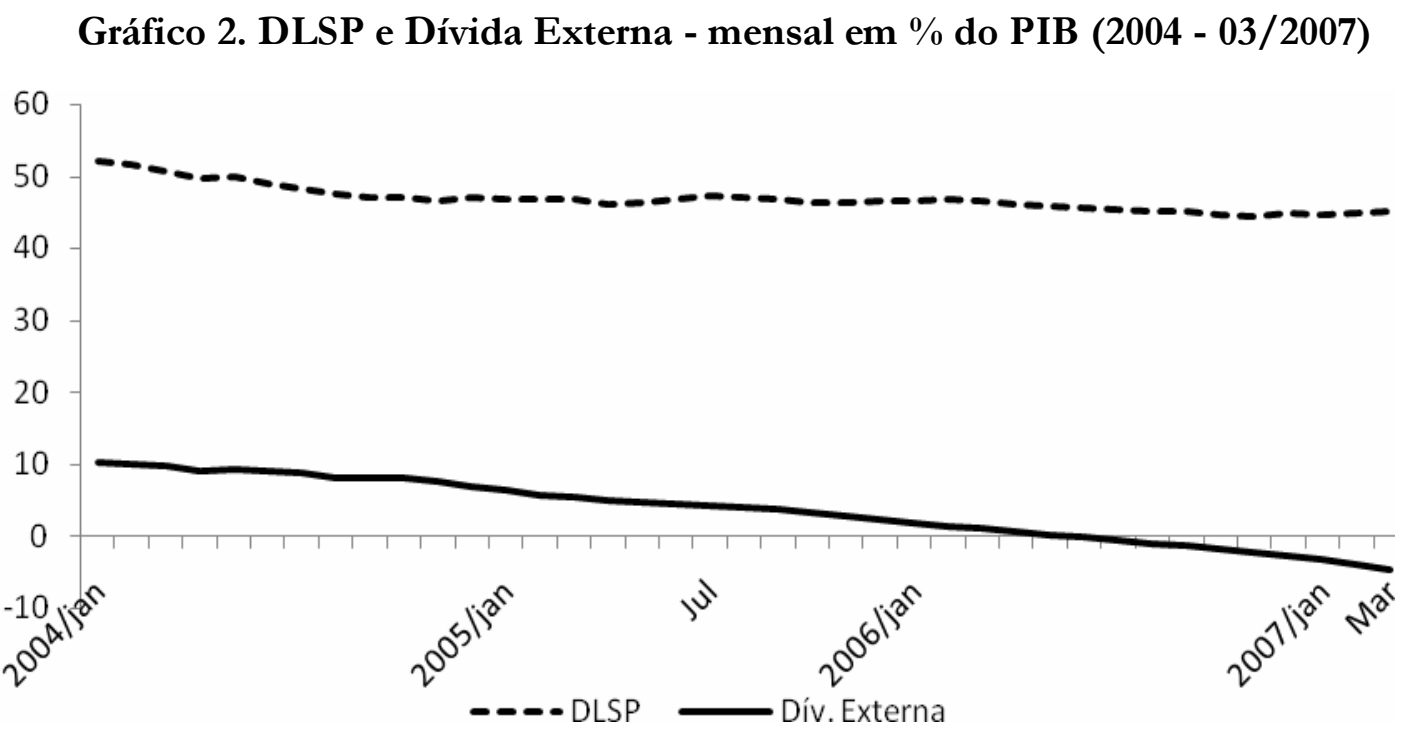

Fonte: Banco Central do Brasil

O terceiro e último componente que relaciona diretamente o câmbio a DLSP é o de reservas internacionais. A aquisição de divisas estrangeiras tem sido feita quotidianamente pelo Banco Central que busca, com isto, conferir maior estabilidade macroeconômica ao país,

${ }^{24}$ A dívida externa bruta, líquida das reservas internacionais, fornece a dívida externa líquida, categoria analisada neste artigo. 
frente a adversidades que possam ocorrer na economia global. Ademais se serena a percepção de risco que formam os agentes e as agências de rating sobre a saúde da economia brasileira, na medida em que o nível de reservas é um fundamento avaliado por estes. Um maior fluxo de investimento internacional é obtido desta forma.

Mas não é apenas para a composição de reservas que o Banco Central atua no mercado de câmbio comprando divisas estrangeiras. A sua atuação tem sido realizada, também, para conter a valorização do real. O real sobrevalorizado tem influências negativas sobre o nível de exportações, podendo levar a uma piora do saldo comercial. Porém, devido aos bons preços das commodities de exportação brasileira, e ao ciclo de liquidez mundial, este efeito nocivo ainda não se verificou.

No caso das reservas internacionais o movimento de valorização da taxa de câmbio é ambíguo. Por um lado, é favorecida a compra de divisas estrangeiras pelo seu barateamento. Por outro, o seu valor - em efeito similar ao que ocorre com o estoque da dívida externa - se reduz, na medida da valorização da taxa de câmbio. As reservas são compostas, assim como o passivo externo, por diferentes moedas. Sua contabilização, porém, é realizada em dólar americano, sendo todas as diferentes moedas a ele convertidas, o que implica, com a valorização cambial, determinado ônus às contas públicas. Este processo passou a ser mais incisivo após 2006, quando a composição de reservas internacionais foi intensificada, como pode ser verificado no gráfico 3.

\section{Gráfico 3. Reservas Internacionais e Dívida Externa Líquida - em US\$ milhões - estoque mensal (2004 - 03/2007)}

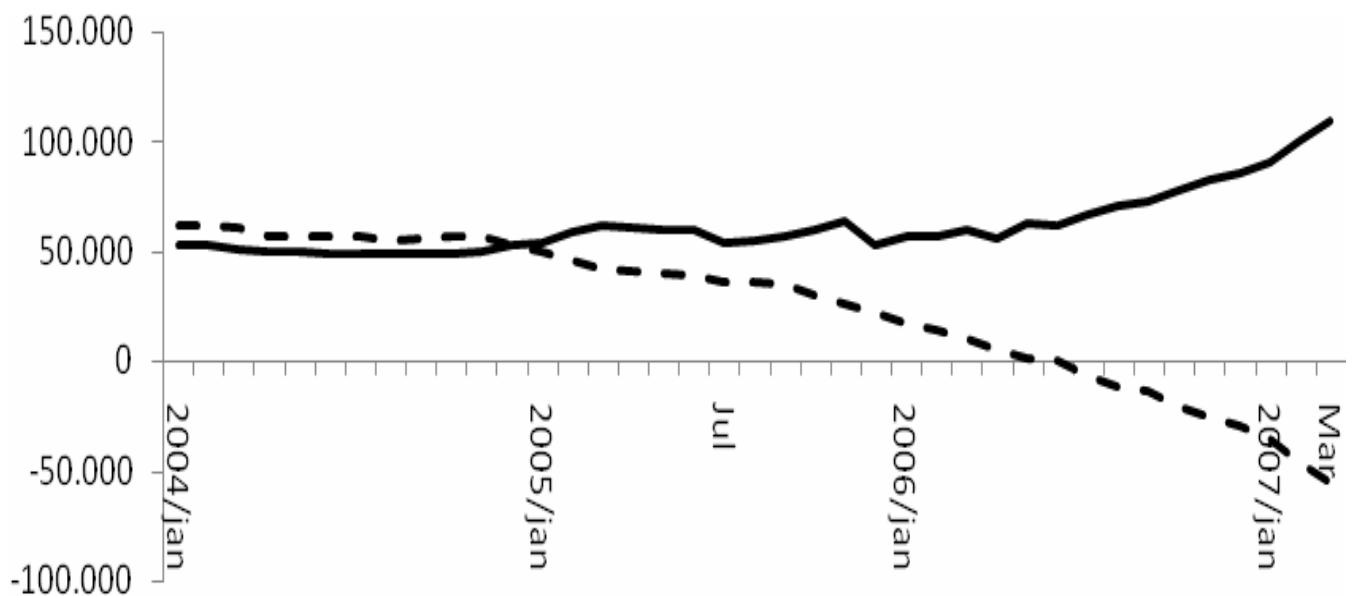

— Reservas - - Dív. Externa

Fonte: Banco Central do Brasil 


\subsection{Os valores do ajuste cambial}

A valorização cambial, pelos caminhos acima apresentados, tem contribuído para a estabilidade dos fluxos dos fatores condicionantes da evolução da DLSP, o que pode ser visto pelos dados apresentados abaixo.

O ajuste cambial da DLSP, representa a correção do valor do estoque de endividamento do setor público derivado das oscilações ocorridas na taxa de câmbio. Com a apreciação do real, o impacto do câmbio sobre a DLSP é favorável à sua redução. Isto pode ser visualizado pelo gráfico 4 .

A permanência da relação DLSP/PIB em torno de 46,8\%, entre 2004 e março de 2007 é auxiliada pelos ajustes cambiais realizados. Somando-os ao superávit primário, tem-se, em parte, a amortização dos fluxos que impactam de forma desfavorável sobre a evolução do estoque da DLSP, elevando-o, como é o caso dos juros nominais e dos passivos contingentes.

O gráfico 4 apresenta - linha em negrito - o ajuste cambial. Na maior parte do tempo o movimento do câmbio fica na parte negativa do plano, o que representa redução do estoque da DLSP.

\section{Gráfico 4. Ajuste Cambial, Variação da DLSP, Resultado Primário - mensal em \% da variação da DLSP/PIB (2004 - 03/2007)}

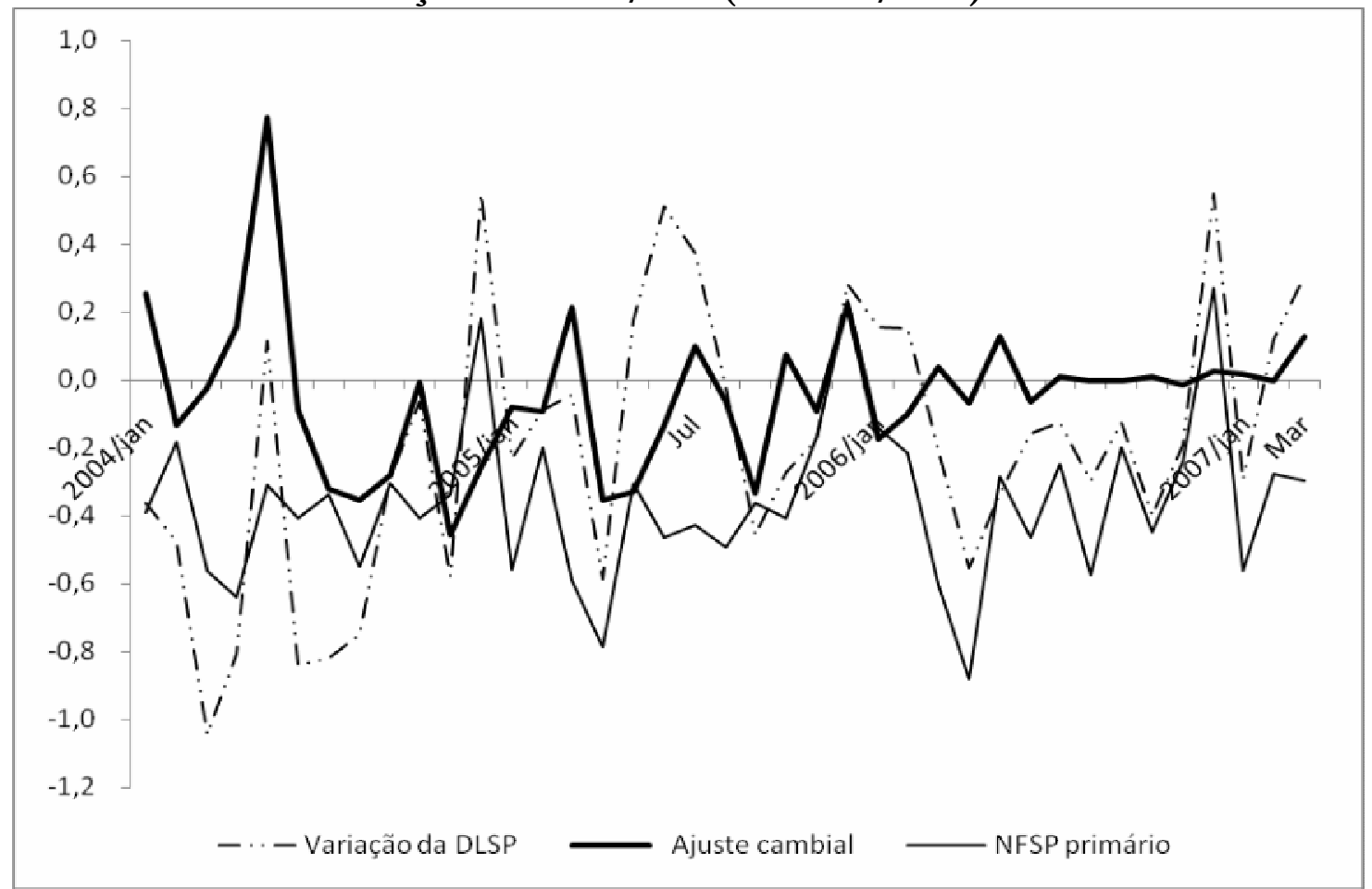

Fonte: Banco Central do Brasil

A tabela 1 abaixo apresenta os valores em milhões de reais do ajuste cambial da DLSP. Os valores negativos contribuem para a redução do estoque do endividamento. Em 25 
dos 39 meses da amostra o ajuste cambial foi favorável à redução do endividamento público. No total o ajuste cambial contribuiu com algo em torno de $\mathrm{R} \$ 36,2$ bilhões para a redução do endividamento.

Tabela 1. Ajuste Cambial - mensal em R\$ milhões (2004 - 03/2007)

\begin{tabular}{lrrrr}
\hline Ano & 2004 & 2005 & 2006 & 2007 \\
\hline Jan & 4466 & -1693 & -3845 & 388 \\
Fev & -2386 & -1891 & -2217 & -46 \\
Mar & -464 & 4369 & 843 & 3038 \\
Abr & 2861 & -7393 & -1538 & - \\
Mai & 14670 & -6875 & 2864 & - \\
Jun & -1696 & -2770 & -1488 & - \\
Jul & -6330 & 2049 & 204 & - \\
Ago & -7023 & -1330 & -71 & - \\
Set & -5621 & -6966 & -52 & - \\
Out & -160 & 1582 & 184 & - \\
Nov & -9253 & -2005 & -365 & - \\
Dez & -5257 & 4720 & 600 & - \\
\hline
\end{tabular}

Fonte: Banco Central do Brasil

\section{Conclusões}

A relação entre a valorização da taxa de câmbio e a dívida líquida do setor público, mostra que, o movimento daquela impactou favoravelmente na evolução desta, durante todo o período. Assim, a velocidade do aumento da DLSP é reduzida e maior estabilidade lhe é garantida.

Não obstante, isto representa uma melhor possibilidade de condução da política fiscal. O ajuste cambial se alia ao superávit primário para a amortização dos juros nominais e para a redução do déficit nominal do setor publico, reduzindo suas necessidades de financiamento.

Ademais as reservas internacionais são superiores ao passivo externo, o que representa uma estabilidade ante os débitos contratados em moeda estrangeira. O país se encontra com fundamentos macroeconômicos mais sólidos, recebendo maior quantidade de recursos do circuito financeiro internacional.

A dívida mobiliária, parcela majoritária da DLSP, está praticamente desvinculada da indexação cambial, o que a concede maior segurança frente a adversidades que porventura ocorram no cenário internacional.

A análise dos dados mostra, portanto, que a apreciação da taxa de câmbio contribuiu, inegavelmente, para a melhora da relação DLSP/PIB, no período 2004 - março de 2007, tanto em seu componente interno, como no externo.

76 